\title{
ABORDAGENS INTERPRETATIVAS DE PESQUISA EM ADMINISTRAÇÃO E MARKETING
}

\author{
Por Rodrigo Moura Lima de Aragão \\ Especialista em Administração pela FGV-EAESP \\ E-mail: aragao_rodrigo@yahoo.com.br
}

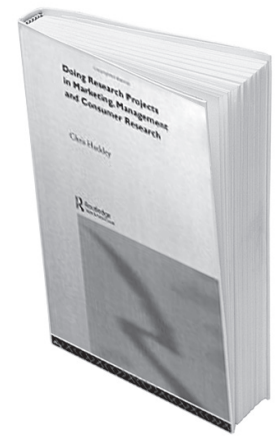

\section{DOING RESEARCH PROJECTS IN MARKETING, MANAGEMENT AND CONSUMER RESEARCH}

De Chris Hackley. Londres: Routledge, 2003. 210 p.

Estudos sinalizam deficiências quanto a aspectos metodológicos na produção acadêmica brasileira em administração ${ }^{1}$ de uma forma geral e em marketing. ${ }^{2}$ Considerando-se que a formação dos administradores e profissionais de marketing no país dirige-se, sobretudo, à demanda das organizações, a presença de tais deficiências é, em parte, compreensível. Sabendo-se ainda que tanto a administração quanto o marketing têm escopo multidisciplinar, entende-se que a construção de um repertório metodológico de pesquisa consistente nessas áreas não é tarefa simples. Estatística, psicologia e antropologia, por exemplo, são fontes comuns a acadêmicos da administração e do marketing e apresentam, cada qual, métodos particulares que exigem, para uma aplicação bem- sucedida, a apreensão de construtos e técnicas específicos.

Contudo, se conduzir a administração e o marketing brasileiros ao cenário internacional de management é um objetivo corrente das escolas de Administração pioneiras do país, é preciso, então, dar a devida atenção à formação dos pesquisadores no que se refere à metodologia de pesquisa nessas áreas. Métodos inapropriados ao objeto de estudo em foco, métodos com fraca sustentação teórica ou empírica, projetos mal estruturados ou mal executados debilitam - senão invalidam - os resultados obtidos, o que interfere negativamente na leitura da pesquisa como um todo e obstrui o reconhecimento, por pares, daquele estudo em particular.

O trabalho de Chris Hackley, Doing
Research Projects in Marketing, Management and Consumer Research, constitui, certamente, contribuição relevante para os que buscam uma base sólida no que diz respeito aos métodos de pesquisa em administração e marketing. A obra, escrita tanto para pesquisadores iniciantes como para os que já têm alguma experiência com pesquisa, dirige-se às abordagens (ou perspectivas, ou tradições, nas palavras do autor) de pesquisa interpretativas.

Os quatro primeiros capítulos do livro reúnem recomendações gerais do autor para o desenvolvimento de um projeto de pesquisa nas áreas de administração e marketing. Neles, o leitor familiarizado com trabalhos que versam sobre metodologia de pesquisa ou, ainda, sobre a produção acadêmica, como os de $\mathrm{Eco}^{3}$ e de 
Cervo e Bervian, ${ }^{4}$ encontrará pontos já discutidos, a exemplo da escolha do tema e das características da escrita acadêmica. O tratamento dado por Hackley a esses pontos, todavia, apresenta peculiaridades da pesquisa em administração e em marketing que outras obras de enfoque mais amplo não contêm. Ao tratar da escolha do tema, por exemplo, o autor, explorando a relação entre objeto de estudo e método, confronta as pesquisas de caráter exploratório com as que visam testar hipóteses, a partir da realidade da administração. Constata Hackley que, para o pesquisador iniciante, a alternativa mais segura é a pesquisa exploratória. Assumir na concepção de um estudo em administração uma relação causal inexistente ou, ainda, ter implícita na pergunta de pesquisa a pretensão de solucionar um problema gerencial são falhas que, para o autor, a opção pela pesquisa exploratória pode evitar.

O capítulo 5 aborda conceitos gerais das tradições de pesquisa interpretativas, sendo também uma introdução ao conteúdo dos capítulos subseqüentes - que exploram, de fato, perspectivas específicas de pesquisa. Hackley define as tradições interpretativas como "[...] conjuntos de premissas operacionais acerca de interpretações que foram em parte explicitados e que são utilizados por pesquisadores no desenvolvimento de corpos do trabalho distintivo de pesquisa" (tradução nossa) e assinala que a postura epistemológica assumida na obra é a de que aquilo que se considera conhecimento é, necessariamente, mediado pela interpretação humana. Para o autor, toda pesquisa envolve interpretação, seja a dos dados primários ou secundários, seja a das experiências do próprio pesquisador, seja a interpretação das teorias e modelos identificados na literatura.
Os capítulos subseqüentes, por sua vez, tratam das seguintes abordagens interpretativas de pesquisa: fenomenologia (capítulo 6); etnografia (capítulo 7); estudos críticos e análise crítica do discurso (capítulo 8); semiótica (capítulo 9); teoria literária, análise da narrativa, feminismo e estudos de gênero, pós-modernismo e pós-estruturalismo (capítulo 10). Com exceção do último capítulo, que se limita a um tratamento sintético das abordagens citadas, esses capítulos têm uma estrutura comum. Apresenta-se a tradição de pesquisa interpretativa em foco, analisam-se tópicos concernentes a essa tradição, exploram-se elementos referentes à coleta de dados e, por fim, discutem-se aspectos gerais da pesquisa realizada sob essa perspectiva específica.

No trabalho de Hackley, dois pontos merecem destaque. O primeiro diz respeito aos exemplos trazidos pelo autor ao texto. Ao longo de toda a obra, apresenta-se ao leitor: como foram aplicadas determinadas abordagens de pesquisa, como se deu a coleta de dados em diferentes projetos, quais dificuldades foram encontradas em certos estudos e quais as soluções desenvolvidas para a superação dessas dificuldades. Esse conjunto, resultado, principalmente, da experiência do autor como orientador e pesquisador, pode ser extremamente valioso ao leitor interessado em aplicar as abordagens de pesquisa interpretativas. A partir dele, é possível ter uma visão dos bastidores dos projetos de pesquisa, o que, em geral, não é acessível pela leitura de artigos publicados em periódicos.

As citações feitas pelo autor ao longo da obra também merecem destaque. O leitor atento observará que se reúnem referências suficientes para o início de uma pesquisa capaz de dialogar com a administração e com o marketing internacionais. Nem todos os estudos relevantes em fenomenologia ou semiótica são citados por Hackley, evidentemente - apenas alguns. No entanto, por meio da análise de suas citações e referências, o pesquisador pode mapear grande parte dos estudos vinculados à abordagem interpretativa que é do seu interesse, em âmbito internacional, o que constitui o primeiro passo para a construção de um diálogo com as pesquisas feitas no exterior.

As abordagens de pesquisa apresentadas e analisadas na obra decerto enriquecerão o repertório metodológico do leitor. Cabe a ressalva, porém, de que a transposição cega de técnicas e modelos deve ser evitada, uma vez que os contextos cultural, econômico e político nos quais se insere uma pesquisa são, muitas vezes, determinantes para as escolhas feitas pelo pesquisador. Assim, é fundamental que o leitor, ao ter contato com as perspectivas exploradas por Hackley, não ignore as diferenças existentes entre o universo de produção da obra e o seu universo particular de produção científica.

\section{NOTAS}

1 Vide BERTERO, C. O.; CALDAS, M. P.; WOOD JR., T. Produção científica em administração de empresas: provocações, insinuações e contribuições para um debate local. Revista de Administração Contemporânea, v. 3, n. 1, p. 147 178, jan./abr. 1999.

2 Vide PERIN, M. G.; SAMPAIO, C. H.; FROEMMING, L. M. S.; LUCE, F. B. A pesquisa survey em artigos de marketing nos Enanpads da década de 1990. In: ASSOCIAÇÃO NACIONAL DE PROGRAMAS DE PÓS-GRADUAÇÃO EM ADMINISTRAÇÃO, 22., Foz do Iguaçu. Anais eletrônicos...Foz do Iguaçu: ANPAD, 19981 CD-ROM.

3 ECO, U. Como se faz uma tese. 14. ed. São Paulo: Perspectiva, 1977.

4 CERVO, A. L.; BERVIAN, P. A. Metodologia científica. 5. ed. São Paulo: Prentice Hall, 2002. 